\title{
Complementary Medicine Has Reached the Centre of Scientific Interest: Some Thoughts on loannidis' Citation Database
}

\author{
Harald Walach \\ Forschende Komplementärmedizin, Medical University Poznan, Poznan, Poland
}

One hears, now and again, especially at times of medical-political campaigning, that complementary medicine is "unscientific." Mostly, this verdict is used by journalists who are referring to so-called "authorities," or by the "authorities" themselves, referring to an otherwise unspecified mainstream consensus. I would like to disentangle the meaning behind this statement and offer a simple fact to prove it wrong.

Not long ago, John P.A. Ioannidis, probably one of the most frequently cited and visible medical methodologists and public health researchers, published a database of the 100,000 most frequently cited scientists worldwide [1]. This database ranks researchers and authors according to their impact in terms of citations, i.e., the extent to which other researchers and authors are making use of their work. This has become a standard way of measuring scientific impact, because it provides us with standardized metrics across disciplines. The database uses the so-called Hirsch index or $h$-index [2]. This is an index that places the output of a researcher, in terms of numbers of publications, into a relationship with the number of citations of their papers that appear in other publications. Thus, a researcher who has an $h$-index of 1 has written as many papers as are cited once or, put differently, whose papers are cited, on average, once. A researcher with an $h$-index of 100 has had each of their papers cited by, on average, 100 other researchers. The $h$-index therefore provides a measure of "usefulness" or "visibility" within the community at large.

\section{KARGER}

() 2019 S. Karger AG, Basel
Now, obviously, there are a couple of pitfalls. If researchers get away with citing their own work a lot and at the same time publish a lot, they artificially enhance their $h$-index, because perhaps 40 or $50 \%$ of the citations are not made by other authors but appear in work by the researchers themselves. In addition, areas where there is a lot of active research, such as clinical medicine or cell biology, will automatically produce more citations of important papers than smaller areas like philosophy or social sciences. Ioannidis tried to avoid such pitfalls by various means, e.g., purging the $h$-index of self-citations and adjusting the ranking to the relative importance in a field. The ranking in the database is therefore the relative ranking of each author with potential distortions having been eliminated. However, there are 2 generic distortions germane to the science metric. First, heavy-handed monographs, that might be central to a field, are not normally taken into account. This is often the case for philosophy, theology, history, and social science. The reason for this is that such monographs are not normally cited in the citation databases used to calculate the index, such as Scopus. The other distortion is, of course, the content. No majority vote can define the value of content, and no numerical index can reflect this value. The $h$-index is a formal measure. How often something is cited is not necessarily indicative of quality. Sometimes canonical texts are cited because authors think they need to do this to get published. Science is prone to fashion as well. Sometimes only established authorities are cited, because younger 
Table 1. Part of the full citation database [1] (CAM authors only)

\begin{tabular}{|c|c|c|c|c|c|c|c|c|}
\hline Author & Institution & $\begin{array}{l}\text { Country of } \\
\text { activity }\end{array}$ & $\begin{array}{l}\text { Papers }{ }^{1}, \\
\end{array}$ & $\begin{array}{l}\text { First }^{2} \\
\text { year }\end{array}$ & $\begin{array}{l}\text { Last }^{3} \\
\text { year }\end{array}$ & $\begin{array}{l}\text { Rank }^{4} \\
\text { absolute }\end{array}$ & $\begin{array}{l}\text { Citations }{ }^{5} \text {, } \\
n\end{array}$ & $h$-factor \\
\hline Ernst, E. & University of Exeter & UK & 2,253 & 1975 & 2018 & 104 & 49,553 & 91 \\
\hline Davidson, Jonathan R.T. & Duke University & USA & 426 & 1972 & 2017 & 1.394 & 23,184 & 78 \\
\hline Kaptchuk, Ted J. & Harvard University & USA & 245 & 1993 & 2018 & 6.545 & 11,914 & 58 \\
\hline Eisenberg, David M. & Harvard University & USA & 127 & 1991 & 2018 & 8.641 & 17,583 & 52 \\
\hline White, Adrian & University of Plymouth & UK & 294 & 1990 & 2016 & 16.714 & 7,113 & 49 \\
\hline Lundeberg, Thomas & & Sweden & 340 & 1983 & 2016 & 17.199 & 8,822 & 51 \\
\hline Linde, Klaus & Technische Universität München & Germany & 276 & 1993 & 2018 & 19.488 & 9,659 & 49 \\
\hline Astin, John A. & California Pacific Medical Center & USA & 50 & 1994 & 2014 & 21.379 & 6,123 & 25 \\
\hline Schwartz, Gary E. & University of Arizona & USA & 264 & 1967 & 2018 & 21.893 & 10,831 & 50 \\
\hline Eloff, J.N. & University of Pretoria & South Africa & 204 & 1997 & 2018 & 23.830 & 3,990 & 31 \\
\hline Kelly, Gregory S. & & & 37 & 1985 & 2011 & 31.037 & 2,133 & 23 \\
\hline Walach, Harald & University of Medical Sciences Poznan & Poland & 246 & 1996 & 2018 & 31.716 & 5,419 & 35 \\
\hline Birch, Stephen & McMaster University & Canada & 244 & 1985 & 2018 & 31.925 & 3,919 & 33 \\
\hline Berman, Brian M. & University of Maryland School of Medicine & USA & 211 & 1986 & 2018 & 34.022 & 8,322 & 49 \\
\hline Lewith, George & University of Southampton & UK & 380 & 1980 & 2018 & 34.830 & 6,576 & 40 \\
\hline Kidd, Parris M. & University of California at Berkeley & USA & 38 & 1976 & 2011 & 36.571 & 2,340 & 19 \\
\hline Wilson, Kenneth H. & Duke University & USA & 76 & 1976 & 2017 & 40.760 & 5,466 & 34 \\
\hline Jonas, Wayne B. & Samueli Institute & USA & 187 & 1992 & 2018 & 42.445 & 4,273 & 30 \\
\hline Kemper, Kathi J. & Ohio State University & USA & 181 & 1988 & 2017 & 45.193 & 3,503 & 33 \\
\hline MacPherson, Hugh & University of York & UK & 143 & 1996 & 2018 & 49.923 & 3,934 & 31 \\
\hline Bell, Iris R. & University of Arizona & USA & 142 & 1984 & 2015 & 51.016 & 3,686 & 33 \\
\hline Oken, Barry S. & Oregon Health and Science University & USA & 121 & 1974 & 2018 & 51.325 & 4,495 & 34 \\
\hline Pittler, M.H. & & UK & 155 & 1997 & 2016 & 53.183 & 5,646 & 43 \\
\hline Patrick, Lyn & & & 21 & 1999 & 2018 & 57.086 & 1,560 & 18 \\
\hline Postuma, Ronald B. & McGill University & Canada & 159 & 1998 & 2018 & 61.018 & 5,408 & 42 \\
\hline Ritenbaugh, Cheryl & University of Arizona & USA & 172 & 1981 & 2018 & 63.248 & 6,947 & 45 \\
\hline Patwardhan, Bhushan & University of Pune & India & 144 & 1989 & 2018 & 64.465 & 3,127 & 28 \\
\hline Krucoff, Mitchell W. & Duke University & USA & 261 & 1986 & 2016 & 66.028 & 12,212 & 47 \\
\hline Boon, Heather & University of Toronto & Canada & 188 & 1988 & 2017 & 69.066 & 4,850 & 35 \\
\hline Aickin, Mikel & University of Arizona & USA & 149 & 1996 & 2014 & 72.040 & 6,082 & 32 \\
\hline Lee, Myeong Soo & & Korea & 430 & 1996 & 2018 & 72.358 & 4,904 & 34 \\
\hline Lao, Lixing & University of Hong Kong. & Hongkong & 247 & 1990 & 2018 & 74.896 & 6,057 & 40 \\
\hline Witt, Claudia M. & Charité - Universitätsmedizin Berlin & Germany & 238 & 2001 & 2018 & 78.849 & 4,591 & 30 \\
\hline Chiesa, Alberto & & Italy & 87 & 1973 & 2017 & 82.390 & 2,663 & 23 \\
\hline Sherman, Karen J. & Kaiser-Permanente & USA & 136 & 1984 & 2017 & 82.542 & 5,349 & 36 \\
\hline Baliga, Manjeshwar Shrinath & & India & 142 & 2002 & 2018 & 83.030 & 2,798 & 30 \\
\hline Verhoef, Marja J. & University of Calgary & Canada & 190 & 1989 & 2016 & 84.314 & 4,490 & 38 \\
\hline Mischoulon, David & Harvard University & USA & 194 & 1992 & 2018 & 91.705 & 4,245 & 35 \\
\hline Smith, Caroline A. & University of Western Sydney & Australia & 135 & 1979 & 2018 & 94.130 & 3,110 & 29 \\
\hline Miller, Alan L. & & & 30 & 1980 & 2016 & 94.421 & 1,262 & 14 \\
\hline Paterson, Charlotte & University of Bristol & $\mathrm{UK}$ & 71 & 1995 & 2017 & 95.130 & 1,498 & 20 \\
\hline Büssing, Arndt & University of Witten/Herdecke & Germany & 207 & 1980 & 2018 & 95.907 & 2,181 & 22 \\
\hline Langevin, Helene M. & Harvard University & USA & 67 & 1999 & 2018 & 98.290 & 2,371 & 25 \\
\hline Creath, Katherine & & & 84 & 1984 & 2017 & 99.709 & 1,672 & 13 \\
\hline
\end{tabular}

The institution and country of activity are given according to the original table, which extracted this information from the last available publication and might not always reflect current affiliations. Small institutions were not listed and so I added these when I could. I also added the country where the original table had been left blank.

${ }^{1}$ As of $2017 ;{ }^{2}$ the first year from which publications were counted; ${ }^{3}$ the last year taken into account; ${ }^{4}$ the absolute rank within the group of the 100,000 most cited authors, purged by self-citations and standardized by field; ${ }^{5}$ the number of citations the author got from others, excluding self-citations, ${ }^{6}$ excluding self-citations.

authors want to make sure to not offend such authorities. There are many other reasons, apart from usefulness and content, for which papers get cited.

The original publication, available online [1], offers a link to supplementary files that contain the original datasets that can be filtered and searched. It is instructive to do this for the field of complementary and alternative medicine (CAM), which is in fact its own professional discipline within the database. If we do this, we find that altogether 44 authors of CAM articles are among the 100,000 most influential authors worldwide. To understand this better, it is important to recognize that altogether there are more than 6.8 million authors out there, i.e., this database of the 100,000 most frequently cited authors represents only about $1.5 \%$ of all scientifically active researchers. I was quite surprised by this finding, consid- 
ering the comparatively small field of CAM research within the larger field of medical and scientific research. Estimating that perhaps 5,000 authors are active in CAM research worldwide, $1 \%$ of these are among these 100,000 most influential writers in this database.

An extract from the database representing those CAM authors is presented in Table 1. There are several observations to be made here. All fields of CAM research are represented, with comparatively high rankings, namely, acupuncture (e.g., Adrian White, Klaus Linde, Brian Berman, and Hugh MacPherson), to homeopathy (e.g., Jonathan Davidson, Harald Walach, and Iris Bell), energy research (e.g., Gary Schwartz and Mitch Krucoff), methodology (e.g., Mikel Aickin and Charlotte Paterson), systematic reviews (e.g., Edzard Ernst, Klaus Linde, and Max Pittler), phytotherapy (e.g., Heather Boon), spirituality and mind-body medicine (e.g., John Astin and Arndt Büssing), placebo research (Ted Kaptchuk), surveys, and nutrition research (David Eisenberg).

It could be helpful to use this database to gauge the "scientific impact" of CAM and CAM researchers against those who would publicly denounce CAM research as unscientific. Anyone can download the original table and search for the names of these people. The prominent skeptics often don't even show up among the 100,000 most important researchers and, if they do, they are perhaps less prominent than they would like others to believe. Daniel Dennett, for example, prominent skeptic and self-declared solver of the mystery of consciousness, ranks 73,779th. Richard Dawkins does not even appear in the Table. Of the 12 members on the scientific board of the association of German skeptics frequently called upon by the press to issue statements regarding the scientific viability of CAM treatments and other supposedly unscientific areas, only 3 appear in the table. This will surely not change the public discourse as this is more about politics than about data and evidence, but it may help to keep it centered.

Now, what does this actually mean? It is worthwhile to remind ourselves that science is, first and foremost, a so- cial enterprise [3-6]. Sure, it involves trying to discover facts about the real world and it does this with a methodology that helps avoid errors and pitfalls. But science cannot be conceived without its social dimension, and the way scientific information is used is the outward reflection of this. After all, which papers are cited? Those that others find useful. Those that can help move thinking and research forward. And those that make a new and unique contribution to a particular scientific field, usually, at least.

Another thought: performing CAM research was an uphill battle for those who started it. The funding streams are far scarcer and narrower than for conventional research. It was difficult, initially, to publish CAM research in mainstream journals, and it took a while for dedicated journals such as Complementary Medicine Research, one of the oldest in the field, to be established. It is a success worth celebrating that CAM research has not stayed in the niche of the small community citing its own findings, otherwise the researchers in this field would have never made it to rank within the 100,000 most frequently cited worldwide. For most of the time, our research findings have not been to the liking of the mainstream community, and they are somewhat begrudgingly accepted and published. Some of the authors who fed into the mainstream narrative of CAM being useless and ineffective were of course welcomed more warmly and quoted more widely, but, by and large, this is not the reason for the success of CAM research.

Some of these researchers have been active for 20 years or more. We show here, in Table 1, that CAM has indeed become mainstream, and it would be unscientific to deny or overlook this fact. It would be wise for everyone claiming that CAM research is unscientific to first take a potentially sobering look into this database to gauge their own standing before they speak on behalf of a community who has possibly not even taken much notice of their own research so far.

\section{References}

Complementary Medicine Has Reached the Centre of Scientific Interest
1 Ioannidis JP, Baas J, Klavans R, Boyack KW. A standardized citation metrics author database annotated for scientific field. PLoS Biol. 2019 Aug;17(8):e3000384.

2 Sidiropoulos A, Katsaros D, Manolopoulos Y. Generalized Hirsch h-index for disclosing latent facts in citation networks. Scientometrics. 2007;72(2):253-80.

3 Fleck L (Trenn TJ, Merton RK, editors). Genesis and Development of a Scientific Fact. Chicago: University of Chicago Press; 1979.
4 Latour B. Pandora's Hope: An Essay on the Reality of Science Studies. Cambridge (MA): Harvard University Press; 1999.

5 Collins H. Case studies of expertise and experience. Stud Hist Philos Sci. 2007;38:667-85.

6 Collins H, Pinch T, editors. The Golem. What Everyone Should Know about Science. Cambridge: Cambridge University Press; 1993. 